\title{
La pequeña Lima: Nueva cara y vitalidad para el centro de Santiago de Chile
}

María Elena Ducci. Escuela de Arquitectura, Pontificia Universidad Católica de Chile.

Loreto Rojas Symmes. Magíster en Desarrollo Urbano.

RESUMEN | Las migraciones recientes hacia Chile constituyen un fenómeno social inédito para el país. Este trabajo se centra en el impacto que están teniendo los peruanos, como grupo migrante mayoritario, en el centro de Santiago, donde han recuperado lugares y comercios semiabandonados, generando una "Pequeña Lima", sector donde los migrantes acuden a conseguir trabajo, alimentarse y divertirse. El trabajo muestra los efectos positivos de este fenómeno en la recuperación y revitalización de zonas centrales, dinamizando el comercio y la ocupación de los espacios públicos. Se reconoce también que la instalación precaria de muchos migrantes en viviendas antiguas del centro está generando problemas de hacinamiento y de acceso a salud y educación, lo cual, dada la inexistencia de políticas sociales orientadas a la inmigración, puede (y empieza a) originar conflictos en el corto plazo.

PALABRAS CLAVE | Centros urbanos, cultura urbana, migración, transformaciones socioterritoriales.

ABSTRACT | The recent migrations to Chile are an unprecedented social phenomenon in the country. This work focuses on the impact of Peruvian migrants, as the major migrant group in Santiago 's downtown, and their recovery of semi-abandoned places and shops, creating a "Little Lima". This is an area where migrants look for work, eat and enjoy themselves. The study reveals the positive effects of this phenomenon in the recovery and revitalization of central areas, and in reinvigorating trade and the use of public spaces. It also recognizes the precarious nature of migrant dwelling in older housing in the center, which creates problems of overcrowding, and access to health and education, which-given the absence of social policies aimed at immigration-can (and is starting to) create short-term conflicts.

KEY WORDS | Urban centres, urban culture, migration, socio-territorial transformation. 


\section{Introducción}

Las corrientes migratorias parecen ir en aumento en un mundo abierto a la globalización, donde la circulación entre países y continentes se hace cada vez más fluida. De acuerdo a Sassen, las migraciones internacionales en gran escala están relacionadas con las condiciones producidas por la internacionalización de la economía mundial y “...son parte de redes económicas, sociales y étnicas más bien complejas. Son flujos altamente condicionados y estructurados” (2003, p. 48). De los Ríos et al. plantean por su parte que en el contexto mundial, en la medida que aumenta la facilidad para el transporte y comunicación internacional, estamos observando una propagación de las políticas restrictivas, un aumento de la inmigración ilegal y la creación de comunidades transnacionales, todo lo cual está generando la reorganización de las corrientes migratorias en el mundo (2005).

Este fenómeno, cuya dimensión ha adquirido importancia desde hace varias décadas en los países del norte, empieza a surgir como un tema inquietante en algunos países del sur (Stalker, 2004; Altamirano, 2004), entre ellos, Chile. Siendo las migraciones internacionales parte de dinámicas económicas transnacionales y geopolíticas mayores, la inmigración debe ser entendida, al menos parcialmente, como "un resultado de las acciones de los gobiernos y de los principales actores económicos privados de los países receptores...” (Sassen, 2003, p. 40).

La OIT destaca que en la década de los 90 las migraciones internacionales de trabajadores se transformaron en uno de los aspectos más destacados de la intensiva globalización de la economía mundial, con un impacto fundamental en la economía y la fuerza de trabajo de más de 100 países (Stalker, 1994).

Por otra parte, la migración transnacional produce cambios cualitativos, tanto en el país de origen de los migrantes - por la ausencia de ellos-, como "...en los encuentros o desencuentros interculturales que necesariamente experimentan los migrantes en los países de destino", entre ellos, la emergencia del racismo y otras formas de exclusión (Altamirano, 2004, p. 3-4; Mazurek, 2009).

En este contexto de grandes movimientos migratorios, ciertos países y ciertas ciudades se transforman en lugares especialmente atractivos para los migrantes y en ellas se empiezan a observar cambios significativos en su economía, en su cultura y en el uso de su territorio. Sobre estos cambios urbanos se centra el interés del presente trabajo.

Santiago de Chile está experimentando muy recientemente los efectos de atracción que produce una economía que crece y una situación de estabilidad política y social que caracteriza al país en el último tiempo. Esta nueva inmigración es un fenómeno inédito en términos de volumen, velocidad y diversidad y está provocando impactos en distintos ámbitos de la vida de la ciudad. Hasta ahora, este fenómeno se está enfrentando con una ausencia de políticas gubernamentales que regulen los temas de vivienda, salud, educación y trabajo de los migrantes y existe un gran desconocimiento de las condiciones reales que enfrentan los recién llegados.

Este trabajo se inserta en un campo de investigación que visualiza las migraciones, como propone Mazurek, como “...un proceso de traslado, más socio- 
psicológico que físico, donde las estrategias son ante todo territoriales" (2009, p. 12), por lo que busca mostrar el impacto que están teniendo las corrientes migratorias sobre el territorio, en este caso, la ciudad capital de Chile. Para ello, se centra específicamente en el grupo migrante más visible, los ciudadanos peruanos. Se trata de mostrar las formas en que estos nuevos migrantes utilizan y se apropian del espacio urbano que ocupan, así como los efectos que están produciendo sobre las estructuras y el funcionamiento de la ciudad. Asimismo, se intenta visualizar algunos de los cambios culturales que están generando los inmigrantes peruanos y observar la forma en que ellos perciben su aterrizaje en tierras chilenas.

La hipótesis básica subyacente es que la llegada y establecimiento de nuevos inmigrantes está teniendo un impacto significativo en algunas zonas del centro de Santiago y en la utilización de ciertos espacios públicos. Al mismo tiempo, está dando origen a nuevas expresiones culturales y comerciales, que están siendo gradualmente asimiladas por la sociedad chilena. Este fenómeno está modificando la imagen de la ciudad y, lo que es más interesante, está sirviendo como fuerza de recuperación de ciertas áreas centrales hasta hace poco abandonadas por los santiaguinos; les está inyectando nuevas expresiones culturales y funcionales, haciendo de Santiago una ciudad más cosmopolita, compleja e interesante.

No se intenta aquí idealizar la situación de los nuevos inmigrantes, los cuales enfrentan múltiples problemas y carencias en su integración a su nueva residencia, pero este análisis nos permitirá indagar en algunos de los procesos de "aculturación" que se generan en estas etapas. Procesos por medio de los cuales los grupos y personas desarrollan contactos interculturales, y que, de acuerdo a Berry (2005), generan un potencial de conflicto que necesita de procesos de negociación para lograr ajustes que beneficien a ambas partes.

\section{Migraciones internacionales}

Las razones por las cuales se están produciendo estos grandes movimientos de personas que salen en busca de mejores horizontes, se relacionan directamente con situaciones en sus países de origen, tales como: crisis económicas con alta inflación, desempleo y subempleo, inestabilidad política o guerras internas, conflictos étnicos, alteraciones climáticas o terremotos (Altamirano, 2004).

Stalker sostiene que no sólo se trata de que exista una mayor cantidad de migrantes y que abarquen un espectro geográfico más amplio, sino que también ha cambiado el carácter de la migración: hoy los trabajadores tienden a ser más calificados y a migrar por períodos más cortos. Analizando las migraciones de trabajadores en el mundo, distingue entre cinco tipos diferentes: los que llegan a establecerse, los que llegan contratados para un trabajo específico, los profesionales, los ilegales y los buscadores de asilo y refugiados (1994: V, 4).

Por otra parte, los estados nacionales han perdido capacidad para controlar la inmigración, control que tradicionalmente estuvo basado en el control de las fronteras y de los individuos, considerando de cierta forma la migración como una 
decisión individual. Sin embargo, en un contexto de globalización y apertura de fronteras a la libre circulación de capital, información y servicios, se hace cada vez más difícil el control de las personas, y se está produciendo una transnacionalización de facto de distintos temas inmigratorios, “...en parte por la reorganización del régimen legal transnacional que ha relocalizado algunos de los componentes de la autoridad estatal en organizaciones supranacionales influidos, entre otros, por la Organización Mundial del Comercio (OMC), los códigos internacionales de derechos humanos y acuerdo binacionales sobre la circulación de mano de obra" (Sassen, 2003, p. 37). A pesar de que muchos países defienden sus fronteras celosamente en discursos patrióticos, éstas están cada vez más abiertas a las fuerzas del mercado y están siendo penetradas mucho más efectivamente por bienes, servicios e inversión, así como por personas (Stalker, 1994). Aunque los estados insistan en tratar las migraciones en gran escala como un "resultado agregado de acciones individuales", estos son flujos altamente condicionados y estructuras que forman parte de redes económicas, sociales y étnicas complejas (Sassen, 2003, p. 48). En este sentido, las políticas migratorias como se han entendido tradicionalmente sólo pueden regular la inmigración en forma parcial, ya que hay fuerzas mayores atrás de estos procesos que no pueden ser controladas directamente por el Estado, relacionadas también con los acuerdos internacionales sobre derechos humanos y con los derechos sociales y políticos que adquieren los inmigrantes después de cierto período de residencia en el país (por ejemplo, de acceso a la vivienda).

Por otra parte, si se considera que hay una serie de otros factores que intervienen en la decisión de migrar ligados a los cambios tecnológicos y al acceso de la información, queda en evidencia la necesidad de repensar la orientación de las políticas migratorias que persiguen disminuir el potencial de conflicto que se genera en torno a los inmigrantes. Mazurek señala como factores que hacen que las personas se decidan a migrar: la influencia de las comunicaciones, la extendida difusión de las imágenes de la modernidad (medios, publicidad), la importancia del núcleo familiar y de la solidaridad familiar y comunitaria. Además, el efecto del imaginario en relación al "otro espacio" produce una idealización colectiva y "redes de idealización" que se transmiten por teléfono, Internet y contactos familiares, abriendo la perspectiva de una movilidad social en relación al entorno (2009, p. 16). "En este sentido, la lógica migratoria, individual, está relacionada siempre a un espacio social, en relación con una situación de comunicación, una lógica de promoción social que necesariamente tiene sus raíces y sus referentes en un territorio determinado" (2009, p. 17).

Algunas de las características que distinguen a la migración transnacional contemporánea son: una creciente feminización, un aumento de migrantes jóvenes, un endurecimiento de las leyes migratorias -especialmente en los países del norte-, la incorporación de migrantes provenientes directamente del campo y un incremento de migrantes no voluntarios o compulsivos (refugiados) (Altamirano 2004, p. 3). Con respecto a la feminización observada en las corrientes migratorias, Sassen (2003) señala que hay una demanda creciente de mujeres inmigrantes que 
están integrando a las mujeres del Tercer Mundo a la mano de obra asalariada y, de acuerdo a información de CELADE, en la actualidad los principales flujos intrarregionales en América Latina tienden a ser feminizados: Nicaragua-Costa Rica (50,1\%), Paraguay-Argentina (56\%), Perú-Chile (60,1\%) (Robert, 2009, p. 88).

El beneficio tal vez más evidente para los países receptores de migrantes es la obtención de mano de obra barata, especialmente para los trabajos de menor calificación (servicio doméstico, labores de construcción) y uno de los resultados positivos que obtiene el país de origen es el eventual retorno de nacionales con mayores calificaciones, especialmente en el caso de migraciones a países del norte, con mayores niveles de desarrollo (EE.UU. y Europa).

Asimismo, una de las ganancias claves para los países de origen de los migrantes es que todos los migrantes envían parte de su salario a sus familiares que quedaron atrás: las "remesas", las cuales se han convertido en un componente de gran importancia para la economía nacional de los países con altos niveles de emigración “...para algunos autores incluso las remesas pueden desempeñar un papel crucial para resolver los cuellos de botella financiero del pasado y para aportar los recursos necesarios para el desarrollo a largo plazo" (Portes, 2009, p. 343).

Aunque la estimación del impacto que tienen sobre la economía de los países de origen las remesas es difícil, la OIT estimó que a mediados de los 90 cada trabajador migrante enviaba, como promedio, mil dólares anuales a su país de origen (Stalker, 1994, citado por Altamirano, 2004). En ciertos países como México, las remesas enviadas desde EE.UU. se han transformado en la segunda fuente de ingresos de divisas al país según el Banco de México, llegando a representar el 2,2\% del PIB en 2003 y es un factor determinante en la reducción de los niveles de pobreza extrema en el país (BID, 2004). Un informe del Banco Mundial señala que el monto de estas transferencias representa el 8,7\% del PIB en Bolivia (972 millones de US\$), y el 7,8\% en Ecuador (3.162 millones de US\$) (Mazurek, 2009, p. 23).

El crecimiento explosivo de las remesas hacia América Latina refleja un mercado laboral totalmente integrado dentro del hemisferio occidental. Dicho de otra manera, las economías de los países desarrollados necesitan las habilidades y la dedicación de los trabajadores de los países de esta región, que hoy no generan puestos de trabajo o ingresos suficientes para sus propias poblaciones (Mazurek, 2009, p. 23).

En relación con el impacto de la feminización de estas migraciones que transforma a las mujeres en proveedoras económicas, se están generando cambios en su posición de género. Así, "Las remesas no tienen sólo una dimensión monetaria sino que también hay un flujo de remesas sociales, que tienen un impacto en las relaciones de género dentro de los hogares y dentro de las comunidades, transformando las concepciones tradicionales de los roles de género y de la imagen de las mujeres" (Roberts, 2009, p. 96).

Un tema en el que también interesa indagar es el del efecto que están produciendo estos nuevos actores de las migraciones internacionales; las reacciones que se observan van desde el rechazo, los encarcelamientos y deportaciones, “...hasta la resignación o relativa aceptación, porque ya no se podrá vivir prescindiéndolos, 
debido a que son absolutamente necesarios para reemplazar la escasez de mano de obra, por las transiciones demográficas tempranas en los países de destino, o porque los trabajos sucios, de alto riesgo, de poco prestigio y salarios bajos, ya no lo desean asumir los nacionales" (Altamirano, 2004, p. 2).

\section{Migraciones recientes en Chile}

Los flujos migratorios hacia Chile han aumentado explosivamente en las últimas décadas y muestran cambios sorprendentes en términos históricos: por primera vez disminuye la inmigración europea y cobra importancia la inmigración de países Latinoamericanos ${ }^{1}$. El Censo de Población de 2002, mostró que en 10 años se produjo un aumento del $75 \%$ de los extranjeros residentes en el país, el mayor crecimiento experimentado en los últimos cincuenta años $(1,2 \%$ del total de la población o ciento ochenta y cinco mil personas).

El origen de los inmigrantes recientes corresponde mayoritariamente a países limítrofes y/o cercanos, destacando, según el censo de 2002, Argentina (26\%), Perú (21\%), Bolivia y Ecuador, aunque fuentes más recientes señalan que la población peruana ha pasado a ser predominante. Un $42 \%$ de los llegados entre 1992 y 2002 provenían de Perú y Ecuador, con un crecimiento del 395\% y 314\%, respectivamente (Solimano y Tokman, 2006).

Stefoni (2002), señala que la atracción que está produciendo Chile para los migrantes en América Latina se explica por dos procesos independientes. Por un parte, los tradicionales centros de atracción para latinoamericanos (Estados Unidos y Europa) han cerrado sus fronteras, con políticas cada vez más restrictivas, provocando la reorientación de los flujos migratorios hacia destinos de acceso más fácil y con oportunidades laborales. Paralelamente, Chile exhibe una relativa estabilidad económica y política, lo que asegura mayores oportunidades de empleo y desarrollo para los recién llegados.

Solimano y Tokman (2006) señalan que son tres las tendencias que caracterizan a los inmigrantes de las últimas dos décadas en Chile: un predominio femenino, una concentración en edades de mayor actividad laboral y un mayor nivel de educación. El proceso de feminización de la inmigración es coincidente con la clara feminización de los movimientos migratorios en el mundo y se evidencia en el 52,2\% de mujeres que conforman la migración registrada en el Censo de 2002. Aunque Argentina, Costa Rica y Venezuela siguen siendo los principales países latinoamericanos receptores de inmigración femenina, desde los años 90 Chile aparece como país de destino desde Ecuador y Perú, la cual trabaja principalmente en servicios domésticos (Robert, 2009, p. 88).

La estructura etaria de los inmigrantes muestra un predominio de los grupos productivos y un ascenso de la escolaridad promedio de los inmigrantes, que se

1 A comienzo de los años cincuenta la inmigración europea constituía cerca del 56\% y la latinoamericana el 23,4\%; para en el año 2002 , los porcentajes se invierten y sólo el 17,2\% de los inmigrantes son de origen europeo, mientras que cerca del 72\% proviene de países latinoamericanos (OIM Chile, 2002; Solimano y Tokman, 2006). 
refleja en un aumento de personas con 10 años y más de escolaridad (de 51,0\% en 1992 a 64,8\% en 2002) y una disminución de inmigrantes con menos de cuatro años de escolaridad (OIM, 2003; Gregorio, 1998; Reyes, 2007).

Por su parte, la distribución de estos colectivos de inmigrantes extranjeros no se da de un modo homogéneo en el territorio nacional y se observan concentraciones específicas en ciertas regiones y ciudades; así los migrantes argentinos destacan en el extremo sur, en tanto que en el extremo norte predominan peruanos y bolivianos. En la zona centro del país y en la Región Metropolitana de Santiago se concentra el $60 \%$ del total de inmigrantes extranjeros, donde destacan peruanos, ecuatorianos, argentinos y bolivianos (Censo 2002; OIM, 2002; Martínez, 2003).

La inserción laboral de los inmigrantes muestra un panorama bastante heterogéneo: la población peruana se encuentra altamente concentrada en el servicio doméstico (43\%); los ecuatorianos en servicios sociales y de salud (33\%), en tanto que los argentinos y bolivianos no se concentran en un tipo particular de empleo, siendo su principal fuente laboral el comercio minorista (17\% y 19\%, respectivamente) (Stefoni, 2005).

El tema de la discriminación es consubstancial a las migraciones, y su importancia se basa en que puede servir de pie para nuevas formas de exclusión y arbitrariedades que pueden generar $-\mathrm{y}$ de hecho producen en muchos paísesestallidos sociales significativos. Para prevenir este tipo de problemas es importante conocer las expresiones del fenómeno y buscar las formas de enfrentarlo. Varios autores han mostrado la existencia de fuerte discriminación, en especial con los migrantes con rasgos indígenas, básicamente peruanos y ecuatorianos, a los que se culpa de ilegalidad y de producir cesantía en el país (OIM Chile, 2002; Stefoni, 2005). Los medios de comunicación en general han contribuido a aumentar la visibilidad de los migrantes, especialmente peruanos, pero también a generar una imagen sesgada sobre los efectos de su presencia en el país.

\section{La migración peruana}

El 70\% de las inmigraciones recientes en Chile provienen de países latinoamericanos, entre las cuales la inmigración peruana destaca especialmente por su rápido crecimiento y por su visibilidad, que responde tanto a su concentración en la capital como a sus características físicas de marcados rasgos étnicos (Stefoni, 2004). Ya en 2005, el Departamento de Extranjería indica a los peruanos como el grupo de inmigrantes más numeroso del país ( $24 \%$ del total).

Altamirano sostiene que Perú es uno de los países del hemisferio sur que produce mayor emigración, la que se estimó en 228.000 personas en el año 2003. "Lo que sucede en el Perú actual es un proceso de emigración semicompulsiva, producida por la recesión económica, pobreza y el desempleo. Una migración laboral que nos ha colocado como uno de los países de mayor emigración en el mundo." Señala también que en los noventa, "peruanos de clase media baja, en particular mujeres, han emigrado a Chile.” (2004, pp. 4, 11). 
La inserción laboral de este grupo era para los hombres, según el Censo de 2002, mayoritariamente en los servicios (26,5\%), comercio $(22,2 \%)$ y en la construcción $(14,9 \%)$, en tanto que las mujeres se concentran en el servicio doméstico $(71,5 \%)$, con un perfil de mujeres jóvenes, con mayores grados de escolaridad, y en general prestando servicios "puertas adentro" (Martínez, 2003; Escrivá, 2002). Stefoni (2002) plantea que el servicio doméstico es un sector económico donde la mano de obra local no quiere trabajar y las mujeres migrantes estarían ocupando lugares de trabajo abandonados por mujeres chilenas, tendencia que tiende a mantenerse en el tiempo (Mujica, 2004). El régimen de trabajo de las mujeres está determinado por la presencia o ausencia de hijos en el país, siendo las mujeres sin familia las que se emplean "puertas adentro", y una vez que han podido traer a su(s) hijo(s) o los han tenido, buscan un trabajo puertas afuera o por horas como aseadoras.

“(...) Y me salí de ese trabajo y ya comencé a buscar puertas afuera para poder estar con mi hija” (Anita, 39 años; 4 años en el país).

Se observan diferencias entre distintos grupos de recién llegados: los que se insertan en la cadena productiva, dedicados a temas como la gastronomía y venta de productos culinarios peruanos (grupo que, como se verá, tiene una fuerte presencia en la ciudad); los orientados a prestar servicios para peruanos y migrantes (banco, telefonía, etc.) y los que se emplean en servicio doméstico o como garzones o meseros (Diario Contigo Perú, 2006).

Como se ha encontrado en todas la corrientes migratorias de importancia en países cercanos, la ilegalidad es un tema constante y, en el caso de la población migrante llegada en los últimos años a Chile desde países como Perú y Bolivia, un fenómeno de gran magnitud que sólo aparecerá oficialmente en las estadísticas nacionales cuando se realice un nuevo censo (2012). Reconociendo el problema que genera la ilegalidad de muchos recién llegados, el gobierno de Chile ha decretado en los últimos años dos amnistías (1998 y 2007), por medio de las cuales ha regularizado la situación de miles de personas. La última amnistía de 2007 benefició a 50 mil migrantes ilegales, de los cuales 32 mil son peruanos (75\%) (La Nación, 23 de octubre de 2007).

Sin embargo, las cifras oficiales que manejan los gobiernos de Chile y Perú dan una idea de la magnitud de la ilegalidad: si en 2003 el gobierno de Chile registraba un total de 35.410 peruanos, el Ministerio de Relaciones peruano estimaba un total de 81.270 peruanos residiendo en Chile (De los Ríos y Rueda, 2005). Asimismo, la información recogida por medio de entrevistas a las organizaciones de migrantes y a través de las historias de vida, muestra que hay una importante subestimación oficial del fenómeno, lo cual además se aprecia en la proliferación de comercios ambulantes en algunas zonas y en la resistencia de muchos de los migrantes por ser entrevistados.

"Ahí en Catedral hacen batidas y si no tienes ningún documento te agarran." (Manuel, 32 años; 5 años en Chile). 
Esta irregularidad genera un campo fértil para abusos laborales y una desprotección social de los recién llegados que requieren salud y educación, además de alojamiento. Es ya evidente que en ciertas zonas de la ciudad (especialmente la comuna de Independencia, cercana al centro) el hacinamiento de los inmigrantes en casas de renta es altísimo, surgiendo problemas similares a los observados en otras ciudades que han pasado por situaciones semejantes (incendios, conflictos con vecinos, etc.).

"El incendio se originó en la construcción de la calle San Pablo 4135, un casa donde habitan unas 20 familias de ciudadanos peruanos y chilenos que componen unas 100 personas" (El Mercurio, 8 septiembre 2008).

“...en calle Compañía esquina Libertad... alrededor de 230 voluntarios pertenecientes a diez compañías de Bomberos debieron concurrir cerca de las 21:00 de ayer a controlar un incendio de grandes proporciones que destruyó completamente la construcción en la que vivían alrededor de cien personas, en su mayoría inmigrantes peruanos, ecuatorianos y colombianos" (La Tercera, 20 de mayo de 2008).

A pesar de que existe un convenio Arica-Tacna, acuerdo que otorga la posibilidad a peruanos de entrar a Chile con visa de turista por 3 meses, este es desconocido por la mayoría de los migrantes y se ha generado una corriente de entradas ilegales de personas al país por pasos no habilitados, por lo cual los inmigrantes pagan entre 100 y 200 dólares (entrevista a líder de organización de inmigrantes peruanos). Los que entran ilegalmente o aquellos a los que se les acaba la visa de turista quedan a expensas de estafadores que han generado un nuevo mercado para los ilegales, como muestra un aviso pegado en una de las columnas del Teatro Municipal: "Extranjeros: Existe apoyo chileno. La Presidenta ordenó facilitar las acciones. Visas de todo. Parejas para matrimonios. Fondos del gobierno para generar negocios. Primera consulta gratis..." (El Mercurio, 17 de febrero de 2008).

Las principales fuerzas que generan la migración peruana hacia Chile se concentran en motivos económicos (mala situación en el lugar de origen), personales (interés por surgir), sociales (redes de familiares y amigos) y territoriales (cercanía geográfica). Esta última surge con fuerza en las historias de vida, ya que la mayor parte de los inmigrantes planean regresar, aunque sea periódicamente al Perú. En primer lugar, surge la aspiración personal por prosperar unida a una percepción de una difícil situación económica en su país y una mejor situación económica y de estabilidad en Chile, además de mejores condiciones laborales, como expresan las citas siguientes:

"Entonces salí de mi país por el motivo económico. Desgraciadamente, como te digo, mi país pasa mucha hambre, muchas necesidades y, desgraciadamente, yo soy profesional pero... me pagaban muy poco y no compensa lo que yo estudié durante cinco años. Estudié parvularia y no me rendía para nada,... y me habían comentado de que acá en Chile se ganaba un poquito más." (Lili, 36 años; 6 años en Chile). 
“(...) Allá en Perú las empleadas domésticas no tienen ningún respeto. No le valoran de nada. No hay ni un beneficio,... no te paga el seguro, nada. En cambio, acá tú tienes tus seguros, sales los feriados (...) Una nana es nada que ver en Perú" (Gladys, 39 años; 1 año y 4 meses en Chile).

En segundo lugar, la existencia de redes familiares o de amistad previas, es decir de migrantes más antiguos que los reciben y facilitan la inserción, resulta un elemento de atracción básico (Feldman, 2007). Ya en 2004, Núñez y Stefoni encontraron que $85 \%$ de los migrantes habían sido precedidos por algún familiar o amigo que les facilitó su inserción, proporción que tiende a aumentar con el tiempo en la medida en que hay más ciudadanos peruanos viviendo en el país.

"Hace ya dos años que me querían traer mis hermanas. Acá tengo hermanas. (...) Mis hermanas me mandaban dinero, como para comprar mi pasaporte, y el pasaje todo..." (Gladys, 39 años; 1 año y 4 meses en Chile).

"A mí me trajo mi hermana. Ella ya tenía años acá. (...) si quieres vente, nomás, yo acá te voy a apoyar en todo, me dijo. Y sí, me apoyó. Inclusive los primeros seis, siete meses que yo estuve acá, ella me apoyaba en todo. Todo. La comida, la pieza, todo" (Manuel, 32 años; 5 años en Chile).

Por último, la cercanía con su país les hace más fácil el retorno o la visita temporal a familiares que quedaron en Perú.

"Entonces aquí hay un sitio más cerca donde puedas trabajar y si te va mal como sea te puedes regresar... que te deporten y toda esa cuestión, pero más lejos imagínate" (Maritza, 42 años; 9 años en Chile).

\section{Una nueva vida}

El inicio de una nueva vida para los migrantes se apoya, en la mayoría de los casos, en parientes o amigos cercanos que los impulsaron a migrar y se transforman en su principal fuente de sostén económico y emocional, facilitándoles un lugar donde vivir y los primeros trabajos.

El primer problema que enfrentan es encontrar un lugar donde vivir. Los altos precios de la vivienda hacen que muchos de ellos arrienden piezas de manera colectiva en casonas semiabandonadas, especialmente en la comuna de Independencia y en Santiago Centro. En opinión de los migrantes entrevistados, muchos propietarios se niegan a arrendar a inmigrantes peruanos:

"Igual claro, a veces es un poco difícil porque te miran y uno les dice: "Ya, ¿̇tiene pieza?” y te miran y te dicen: "No, no hay pieza. ¿Son peruanos?”. (...) Uno ya sabe que no quiere peruanos" (Maritza, 42 años; 9 años en Chile).

Estas residencias colectivas se transforman en lugares donde se hacen nuevas amistades con las que se comparte el tiempo libre y se establecen redes de apoyo mutuo entre migrantes. La mayor parte de los peruanos añora la comida de su país 
(la comida chilena les resulta insípida) y muchos se quejan de la mala calidad de la atención de salud y educación.

"Sabes que la salud acá en Chile es bien mala oh. (...) la salud allá está mejor que acá. (...) te juro que yo he ido a la posta central, y era obsoleta total. Pacientes por los pasillos. (...) la salud deja mucho que desear aquí" (Manuel, 32 años; 5 años en Chile).

“(...) En el colegio la enseñanza aquí es pésima (...) acá en Chile. No es como en Perú la enseñanza. Mi hija tiene 14 (...). Hemos comparado cuadernos, cuando ella entró recién acá a primero, con cuadernos de allá y ha bajado" (Anita, 42 años; 4 años en Chile).

Un fenómeno interesante es el que las mujeres peruanas, mayoritarias entre el grupo migratorio, expresan sentirse más libres en esta nueva vida, con menos presiones familiares y con posibilidades de hacer lo que quieren. Este fenómeno ha sido notado por diversos estudios, tal como lo plantea Robert (2009) y está cambiando las relaciones internas de las familias.

“En Perú yo (...) no era libre como acá. Acá yo soy sola, nadie me dice lo que haga, yo salgo y es muy diferente (...) entonces tú ya misma buscas qué es lo que te conviene, qué es lo que no te conviene y todas esas cosas. O sea, como que te sientes más libre" (Anita, 42 años; 4 años en Chile).

Es asimismo manifiesta la solidaridad que se desarrolla entre los compatriotas, rasgo que destacan en las entrevistas y que resulta una herramienta fundamental para facilitar la inserción a su nueva vida: “...las alianzas familiares, las identidades étnicas y regionalistas, la vecindad, la lealtad, la solidaridad y la reciprocidad entre los migrantes, se convierten en los recursos sociales más importantes para desarrollar actividades económicas" (Altamirano, 2004, p. 28). Un "paisano" pasa rápidamente a tener categoría de casi hermano y persona de confianza:

“...los peruanos sí se ayudan (...). Se prestan bonos, nos prestamos bonos. Por ejemplo, ponte que yo esté asegurado, ¿ya?, entonces yo le presto mi tarjeta de peruano y él paga el bono. Y con mi tarjeta se puede atender el amigo. Eso es clásico (...) también (...) allá en el caracol, hay bastante negocio peruano, ¿cierto? Legalmente esa huevá está constituida por muchos empleados, pero son empleados fantasma. Sólo para regularizar tus papeles. Pero ese contrato que te ha hecho tal persona, tal peruano, tú tienes que pagarle. Gratis no te lo hace. Pero igual ambos ganan" (Manuel, 32 años; 6 años en Chile).

Un rasgo común a todos los migrantes peruanos es el fuerte sentido de pertenencia y el orgullo que sienten de su cultura y país, a pesar de que reconocen que Perú no les está brindando en este momento oportunidades reales de desarrollo. Esto se palpa en todas las entrevistas e historias de vida realizadas y está relacionado con la fuerza de la cultura peruana, con trazos heredados directamente del imperio de los Incas. Esto lo expresa Altamirano refiriéndose a los emigrados: “...el peruano no pierde su peruanidad en el exterior, y que su amor por la patria se acrecienta fuera 
de nuestras fronteras. Las pruebas que demuestran este comportamiento están en las grandes paradas que se realizan en fiestas patrias, las procesiones del Señor de los Milagros, los aniversarios de fundación de sus instituciones y la celebración de los santos patrones de cada pueblo y cada ciudad, pequeña o mediana” (2004, p. 21).

Cuando se trata de autodefinirse en relación al chileno, los migrantes peruanos destacan lo que consideran sus cualidades positivas como pueblo, pero también muestran sus falencias, las que, según ellos, explican la discriminación de la que muchos se sienten objeto. Entre los aspectos positivos de la forma de ser de los peruanos señalan su sentido de comunidad, su espíritu festivo, su talante dialogador y bromista y la buena educación.

"Nosotros quedamos con la nostalgia del sentido de comunidad que tiene el Perú, que aquí no se da. Porque allá el sentido de comunidad es tan fuerte, que por eso yo creo que la gente pasa de fiesta en fiesta. Porque allá todo lo celebran (...) Y aquí eso es difícil que se dé" (Luis, 52 años; 19 años en Chile).

Entre las actitudes negativas mencionadas se encuentra la tendencia a tomar en exceso, la violencia, el desorden, falta de aseo y la improvisación en oposición a lo que consideran la cultura ordenada de los chilenos.

“(...) En Perú es muy diferente que acá. Allá la gente es más violenta (...) en Perú principalmente se practica la violencia con el contacto del licor, de la bebida alcohólica (...) con más frecuencia" (Wilder, 33 años; casi un año en Chile).

“(...) He visto muchas situaciones de peruanos acá que le hacen mucho a la bebida. A mí me da vergüenza pasar por el centro porque (...) he visto mujeres así borrachas (...) o peleando, o así mal vestidos, todos cochinos (...)" (Anita, 42 años; 4 años en Chile).

En casi todas las situaciones de migraciones masivas, los ciudadanos del país de acogida muestran reacciones contrarias a los nuevos migrantes, las que a veces, como ha mostrado en los últimos años la prensa española, llega a extremos de violencia y agresión inusitada. Altamirano ha observado que los padres de niños en los países de destino se quejan de la calidad de la educación, que es deficitaria, en parte, por la presencia de niños de migrantes peruanos (2004, p. 27).

Chile no es la excepción y muchos de los migrantes peruanos se sienten discriminados por la población chilena, la que atribuye a los peruanos, entre otros males, la escasez de trabajo en el país. Mármora (2002) explica que la percepción que se tiene sobre los migrantes es negativa porque es una reacción espontánea que se produce ante lo extraño, lo que es de afuera. En la discusión final se retoma este tema, que es expresado así por un entrevistado:

"Yo de la discriminación me di cuenta en el trabajo que estoy ahora. Sabía todo lo que sale en la tele, lo que se escucha así, pero a mí eso no. Sin embargo, ahí en el gimnasio (...) llega un gallo y (...) me trató mal eso sí pos (...). Es que la gente te discrimina no solamente al hablar, sino que discrimina al no mirarte, al no pescarte"(Luis, 52 años; 19 años en Chile). 
Como una forma de enfrentar esta nueva vida y haciendo honor a su espíritu gregario, los migrantes han generado una serie de organizaciones que se dedican a dar apoyo y facilitar la inserción de los recién llegados al país. En 2007, de acuerdo al Consulado Peruano, existían 12 organizaciones, muchas de las cuales apoyan publicaciones como el Diario Contigo Perú, la principal voz de los migrantes peruanos en Chile. Estas asociaciones voluntarias forman parte de las "estrategias colectivas de sobrevivencia” (Altamirano, 2004) que desarrollan los migrantes, y se asientan en la familia y en las organizaciones multiculturales, las que se convierten en las bases sociales para organizarse y enfrentar problemas existenciales como la necesidad de encontrar trabajo, construir una vivienda, acceder a la medicina tradicional o acceder al ambiente social y cultural para encontrar la pareja matrimonial.

Frente a la ola de migraciones que se ha producido en los últimos años en el país ha surgido con fuerza la presencia de una institución que da apoyo de todo tipo a los migrantes, desde alojamiento cuando están recién llegados, comida, hasta ayuda para conseguir trabajo. Todos los migrantes saben de este lugar y de la existencia de la Madre Fresia, una religiosa perteneciente a la "Parroquia Italiana y Latinoamericana", localizada junto al Parque Bustamante. Este lugar “...convoca no sólo a los peruanos, sino a toda la gente que ha llegado en los últimos años... bolivianos... ecuatorianos... y entonces ahí uno se siente como más en casa” (Luis, 52 años; 19 años en Chile).

"Yo, hasta donde tengo entendido, hay (...) una parroquia, que se llama la Parroquia Italiana. Esa también ayuda, sobre todo a los peruanos. La cara visible de eso es una tal Madre Fresia, he escuchado. No la conozco, pero ella se encarga (...) de ayudarte, de ver por tu salud, te ayuda pos" (Manuel, 32 años; 6 años en Chile).

“(...) la Madre Fresia, (...) creo que ella es chilena me parece. Ella le da la posibilidad a muchas personas, más que todo a mujeres peruanas, de obtener un trabajo en casa... Hay muchas personas que acuden ahí, y van, reciben charlas, cursos, algunos talleres de lo que es el trabajo en casa, y desde luego ellas se encargan de darles una oportunidad. Conseguirles un empleador" (Wilder, 33 años; casi un año en Chile).

Es interesante notar que esta institución, y en especial la Madre Fresia, se han convertido en un eje importante para los migrantes de menores recursos, y las misas dominicales de la parroquia son concurridas por gran cantidad de migrantes, lo que las ha transformado en un evento social para los recién llegados.

\section{Fiesta y celebraciones}

La importancia de la fiesta para los migrantes se aprecia en la gran cantidad de locales que congregan, especialmente viernes y sábados por la noche, a muchos recién llegados que se reúnen para bailar, tomar cervezas y compartir. Las personas entrevistadas reconocen como sus centros de reunión a la calle Catedral, entre Puente y Bandera, y locales del sector de Santiago Centro e Independencia, entre los que destacan El Palacio de San Pablo y el Melody, donde llegan migrantes de todas las edades a celebrar. 
"Donde nos reunimos más son en las discotecas, en los restaurantes, en los Chat peruanos - porque hay Chat donde van puros peruanos; y Catedral pos, que es la calle típica de acá de los peruanos" (Manuel, 32 años; 5 años en Chile).

Para distraerse también asisten a parques y plazas donde se reúnen con otros migrantes.

“Mira, en mi tiempo libre, algunas veces (...) voy, por decir, al Parque O’Higgins. Me gusta ir allá. Con amigos, entre 3, 4. A veces vienen amigas. Nos vamos, paseamos un rato, y luego regresamos. Para estar, como se dice, descansado para trabajar al siguiente día. Vamos a servirnos una bebida, un helado, un postre... Así. Tomamos fotografías..." (Wilder, 33 años; casi un año en Chile).

Sin embargo, además de estas formas básicas de celebración de fin de semana, los migrantes peruanos han importado a Chile algunas de sus celebraciones nacionales más importantes, las cuales están apareciendo cada vez con mayor fuerza en los medios por la cantidad de personas que congregan y por el atractivo espectáculo que generan, situaciones poco comunes en la cultura chilena. Estos eventos se promocionan a través de radios, diarios y carteles de difusión en distintos locales a los que asisten peruanos, principalmente los localizados en calle Catedral y alrededores. Así, se celebran en el corazón de Santiago, su catedral, las Fiestas Patrias peruanas (28 y 29 de julio) con música, bailes típicos, gastronomía, etc. y una alta afluencia de público.

Otra de las fiestas tradicionales de los Incas que han llegado a Santiago de la mano de los migrantes peruanos, es la de Inti Raymi, la fiesta del nuevo sol, en la que los pueblos de la tierra lo celebran y agradecen con ceremonias tradicionales, ofrendas, relatos, música, danzas, vigilia, recibiendo el lucero del alba y el nuevo sol (Cultura en movimiento, 2007).

Sin embargo, la celebración más importante y masiva de la comunidad peruana inmigrante es la Procesión del Cristo Morado, venerado como el "Señor de los Milagros", la cual se realiza el último domingo de octubre y reúne a la comunidad peruana en torno a su gastronomía, música y bailes.

En esta celebración, el "Señor de los Milagros" es transportado en andas en una procesión que dura más de seis horas, desde la Catedral de Santiago hasta la Parroquia Italiana en el Parque Bustamante, recorriendo así parte importante del centro de la ciudad, por calles que se visten de morado. Esta festividad del también llamado "Cristo Moreno" es organizada por la Comunidad Cristiana Peruana Santa Rosa de Lima, fundada en 1993 en Santiago. Congrega a más de 8.000 peruanos y personas de otras nacionalidades y es una demostración evidente de la religiosidad del pueblo peruano que los inmigrantes traen consigo como elemento cultural constitutivo de su identidad. 
FIGURA 1 | Procesión Señor de los Milagros

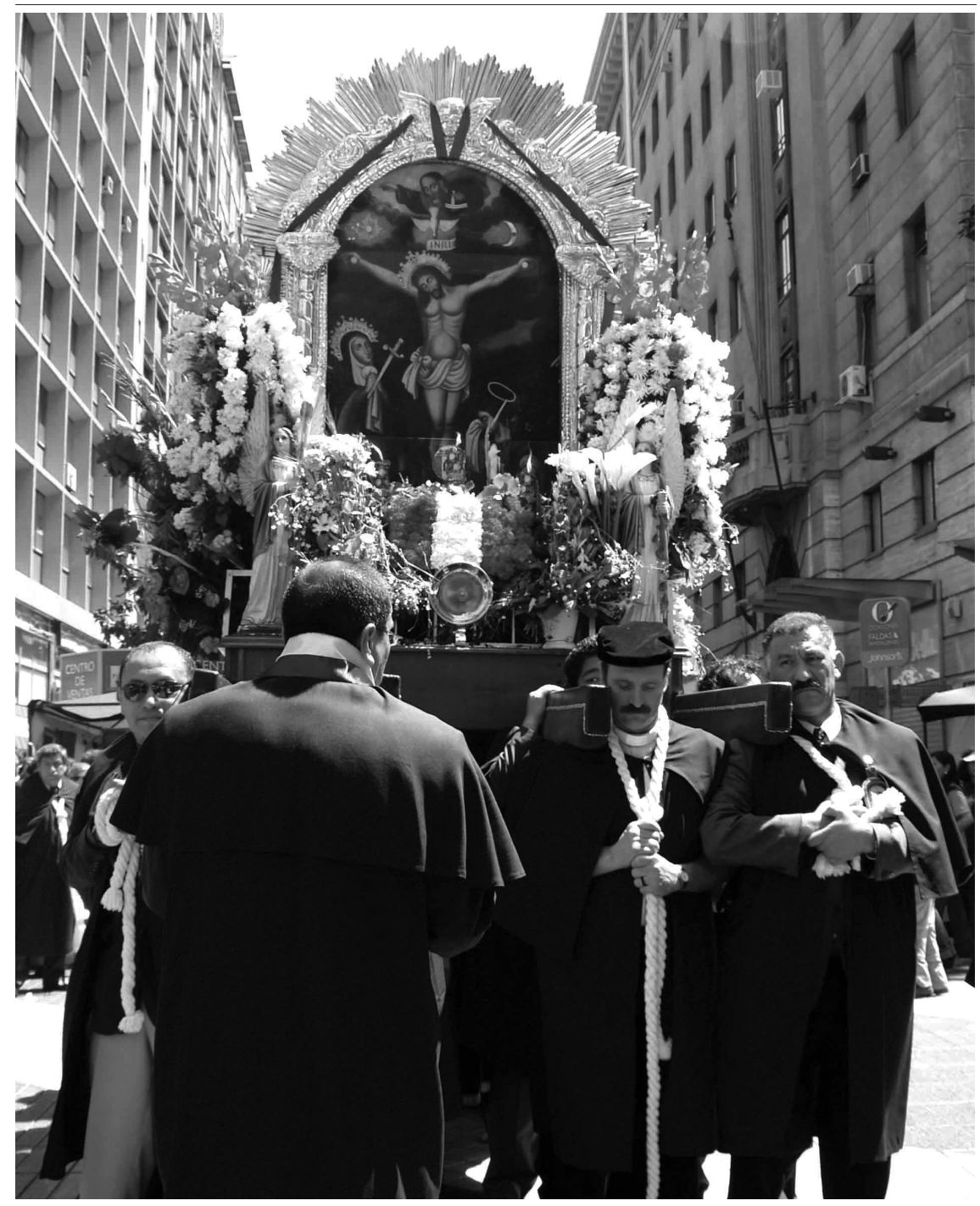

FUENTE FABIOLA ORTIZ.

La importancia que tienen estas celebraciones en la vida de los peruanos se manifiesta en el sorprendente crecimiento de éstas en los últimos años, así como en el aumento del número de asistentes, en la ocupación de nuevos espacios en la ciudad y en la visibilidad y espectacularidad de las mismas, al congregar vestimentas típicas, colorido, manjares y música del Perú. 


\section{Impactos en la ciudad. Ocupación y apropiación del espacio: la Pequeña Lima}

La migración peruana reciente está generando importantes impactos en la ciudad de Santiago, algunos de los cuales son más evidentes que otros. Las principales manifestaciones de la presencia de inmigrantes peruanos en la ciudad se centran en la proliferación de restaurantes peruanos, en la ocupación de algunas zonas de la ciudad como la calle Catedral y cercanías, sectores de Independencia y pasillos de la Vega Central. También se expresa en el surgimiento de centros de reunión de migrantes como la Calle Rivera (comuna de Independencia), en la celebración de algunas fiestas nacionales propias del Perú que han adquirido gran fuerza, y en la aparición de publicaciones y organizaciones propias de los migrantes que manejan sus temas de interés. Analizaremos aquí especialmente la situación del área inmediata a la catedral, el baluarte más visible de este nuevo fenómeno.

Una de las primeras señales fue el surgimiento gradual de restaurantes de comida peruana, los cuales se han ido instalando en diversas zonas de la ciudad, y se orientan a públicos de todos los niveles socioeconómicos. Así, hay restaurantes peruanos destacando entre los más elegantes de la ciudad (Astrid y Gastón, El otro sitio), otros orientados a la clase media (Manuel Montt, Seminario), y gran número de fondas y restaurantes populares instalados en los alrededores de la Pequeña Lima, en Independencia y hasta en la Vega Central, el mercado de productos frescos más grande de la ciudad. Siendo la comida peruana uno de los elementos más claramente distintivos y refinados de su cultura, no parece extraño que los restaurantes sean uno de los íconos de su arribo al país.

La manifestación de la presencia peruana que aparece más fuertemente en los medios y en el imaginario nacional es la concentración de grupos populares de migrantes, muchos de ellos buscando trabajo, en el costado norte de la catedral de Santiago, sobre la calle Catedral. Desde mediados de los 90 empiezan a verse, en el corazón de la capital, algunos pequeños grupos de migrantes que poco a poco van haciéndose más numerosos y notorios.

\section{FIgURA 2 | Peruanos en calle Catedral}

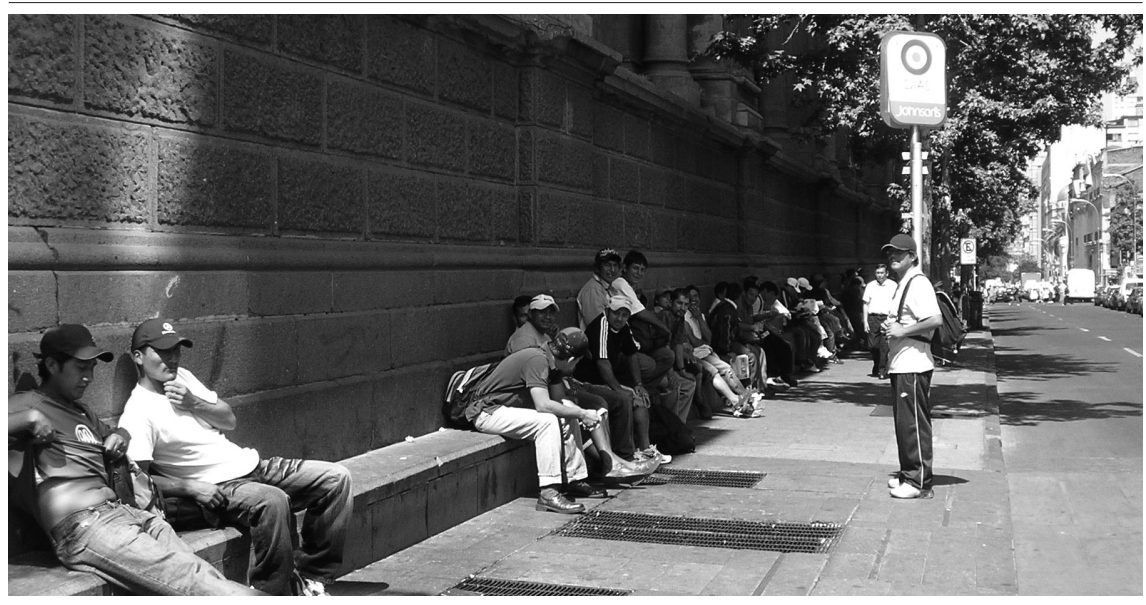

FUENTE AUTORAS. 
"No ves que van a parar todos ahí a Catedral, los hombres especialmente a buscar trabajo. Entonces van ahí y vienen y te contratan. Vienen hasta chilenos. Chilenos vienen y te dicen: 'tengo una obra y necesito tanta gente'" (Maritza, 42 años; 9 años en Chile).

Lo que al principio se vio como grupos de recién llegados que se reunían para conseguir trabajo e intercambiar información se ha ido convirtiendo en una situación constante de personas sentadas esperando alguna oferta de trabajo o paradas en pequeños grupos intercambiando información. Esta presencia se fue complementando con una gradual ocupación de las edificaciones aledañas por locales destinados a la venta de productos y comida peruana, a servicios telefónicos y de envíos al extranjero. Actualmente, tanto sobre la calle Catedral como por los pasajes y galerías aledañas se ha extendido este proceso que sigue creciendo en la medida en que aumentan los migrantes que llegan al país. Poco a poco, los comercios de los alrededores han sido ocupados por locales orientados a los migrantes y muchas de las antiguas casonas cercanas están siendo transformadas en pensiones donde se arriendan cuartos a migrantes (Stefoni, 2004). Tan fuerte es este proceso, que el área inmediatamente al norte de la catedral ha pasado a ser conocida como la "Pequeña Lima", y se ha transformado en lugar de encuentro, de intercambio y de recreación para los migrantes - mayoritaria pero no exclusivamente- peruanos. Este fenómeno de los centros urbanos, cívicos y religiosos actuando como centro de gravedad para los migrantes ha sido observado en distintas ciudades del mundo (por ejemplo, en una esquina de la plaza de Cataluña de Barcelona se reúnen los migrantes latinoamericanos) y Santiago no ha sido una excepción. Desde el principio, la Plaza de Armas fue ocupada por estos nuevos migrantes, concentrándose en calle Catedral la oferta de productos y servicios destinados fundamentalmente a peruanos. La periodista Fabiola Ortiz lo explica así:

“... la sensación de cobijarse en la pared de una iglesia, la mayor y principal iglesia, guarecerse al alero de la casa de Dios, donde quizá la sensación de que te echen o violenten es menor y la sensación de recibir ayuda es mayor" (Diario Contigo Perú).

Inicialmente existió oposición de parte de los vecinos y comerciantes chilenos por la llegada de peruanos al sector, diversos medios acusaban a los peruanos de fomentar el desorden, atentar contra el ornato y la tranquilidad y espantar clientela, llegando incluso a intentar prohibirles apostarse libremente en ciertos lugares (Diario Latín América, 2002). A pesar de todos los prejuicios en torno a calle Catedral y su entorno, hoy es el principal centro de reunión y entretención de los peruanos, congregando a esta comunidad no sólo por motivos comerciales, sino también para buscar trabajo y encontrarse con sus pares. Hoy la presencia de los migrantes se ha transformado en un motor de reactivación del área y así es admitido por muchos comerciantes, que reconocen que esto ha permitido recuperar un espacio céntrico de la ciudad que estaba claramente deprimido. La Pequeña Lima, 
mientras tanto, se ha convertido en el principal centro de reunión de la peruanidad y ha dotado de una nueva conformación, tanto física como funcional, a la zona inmediata a la catedral.

"Me encanta, me fascina [ir a la calle Catedral]. Estar ahí, porque hay sitios de Internet, hay cabinas telefónicas, donde van puros peruanos... y colombianos, ecuatorianos, pero más peruanos. No sé, escuchar palabras que sólo escuchas en Perú, costumbres, ¡como que te anima un poco acá! (...) Todos los días paso por Catedral, te lo juro" (Manuel, 32 años; 5 años en Chile).

La nueva vida que tiene la calle Catedral y su entorno ha reactivado con fuerza esta zona, en especial los fines de semana, lo que contrasta fuertemente con la baja o nula actividad comercial de otras zonas del centro de Santiago ("Catedral, el barrio en movimiento", Diario Contigo Perú, 2006).

FIGURA 3 | Almacén peruano, galería calle Catedral

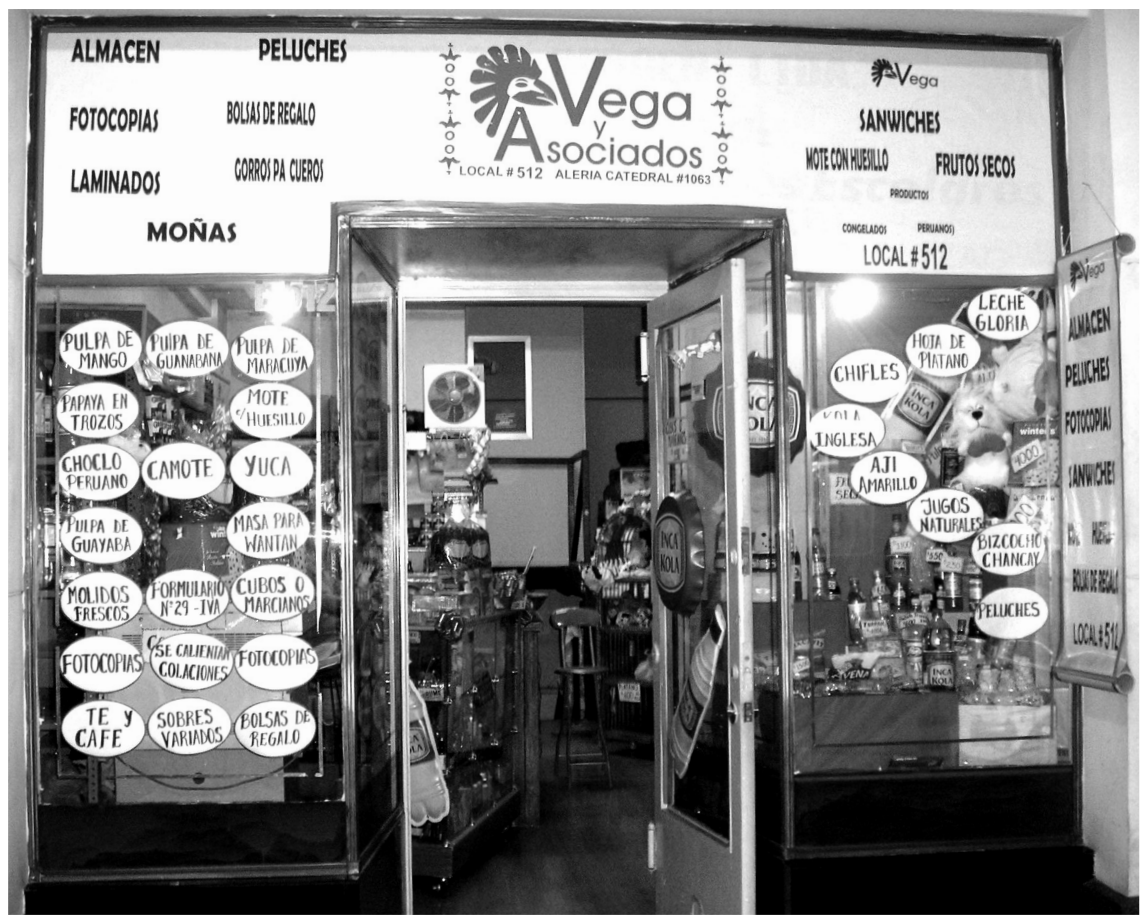

FUENTE AUTORAS.

Uno de los aspectos interesantes de la transformación que ha experimentado esta área central es un radical cambio en su apariencia; los locales ocupados por migrantes y dirigidos a ellos han adoptado una estética y colorido propio de sus países, y muchos de los locales podrían estar insertados en el centro de una ciudad peruana. 
Más allá de la cantidad de locales comerciales destinados a peruanos, llama la atención la apropiación que han hecho del espacio, la cual se refleja en los colores, olores, música y principalmente en la presencia mayoritaria de migrantes, que han hecho de éste un lugar propio, haciendo sentir muchas veces a los chilenos en un territorio desconocido.

El estudio detallado de los usos del suelo de la manzana localizada inmediatamente al norte de la catedral, entre las calles de Puente y Bandera, mostró una desocupación y decadencia de muchos locales, en paralelo con la aparición de nuevos usos, que van desde comercio informal (comida), hasta comercios establecidos en locales al interior de las galerías: abarrotes, restaurantes peruanos, centros de llamados e internet, locales de envíos de dinero y discotecas, todos orientados a inmigrantes y, muchos de ellos, particularmente a peruanos (Ver figura 4).

\section{FIGURA 4 | Usos comerciales calle Catedral}

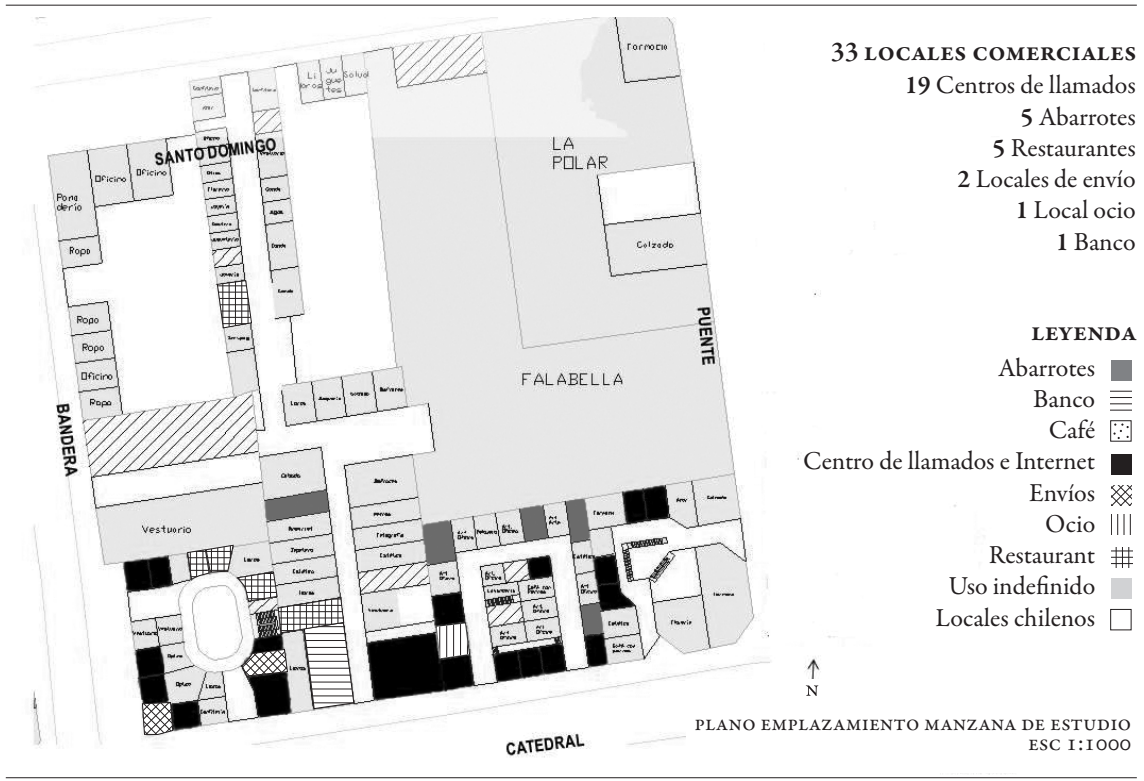

FUENTE ELABORACIÓN PROPIA.

El levantamiento de todas las galerías comerciales de la manzana mostró una fuerte presencia peruana, sobre todo en los locales interiores. El ejemplo más notable de esa ocupación comercial lo presentó la Galería Bandera Centro (Bandera esquina Catedral), un caracol comercial con una fuerte presencia de locales orientados a peruanos. Como se aprecia en el figura 6, en diciembre de 2007 había 40 locales peruanos, 30 locales chilenos y otros 27 locales desocupados, muchos de los cuales servían de bodegas a los propios restaurantes peruanos de la galería. Destaca asimismo que 17 de los 40 locales peruanos estén destinados a centros de llamadas e Internet, usos muy apreciados por los inmigrantes. Por otra parte, es notable, como se aprecia en las fotografías, la fuerte influencia de la cultura peruana en el diseño y colorido de la propaganda de los locales comerciales. 
FIGURA 5 | Galería Bandera Centro

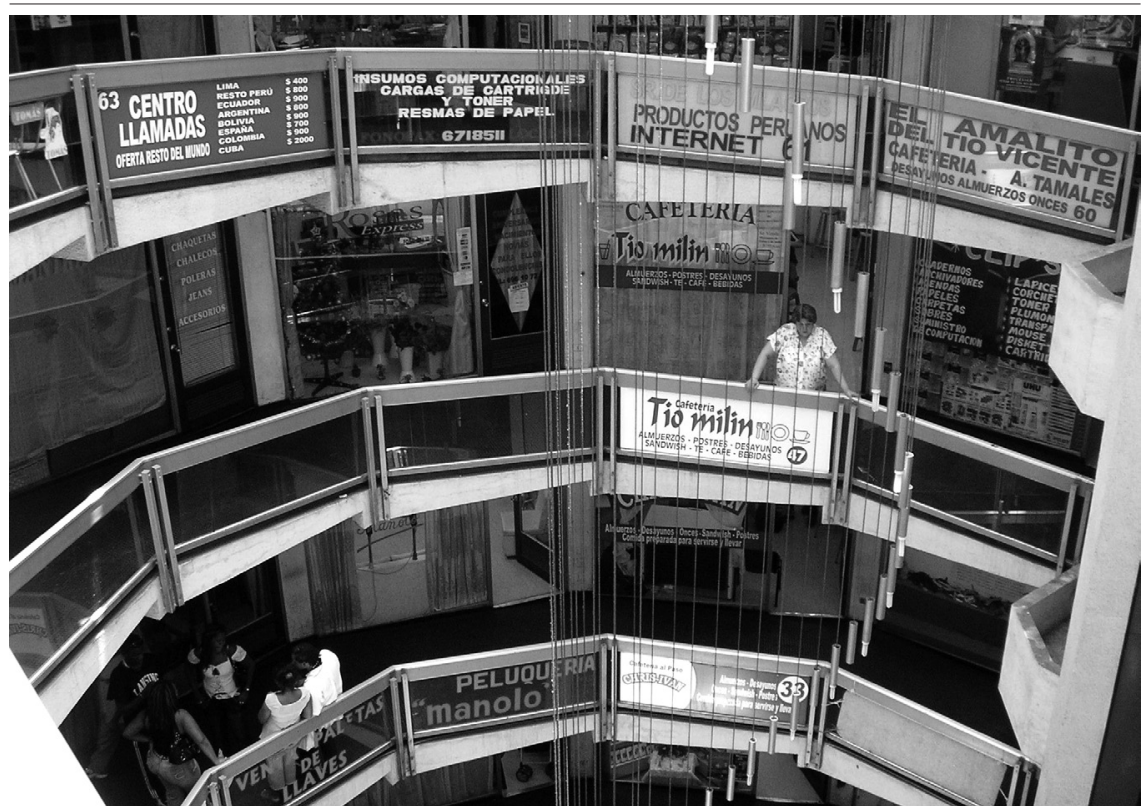

FUENTE AUTORAS.

Durante el transcurso de esta investigación, la velocidad del proceso de cambio de usos en el área quedó evidenciada: entre noviembre de 2007 y enero de 2008, la Galería Bandera Centro pasó a ser ocupada por completo por comerciantes peruanos, los cuales se formalizaron rápidamente ante una fuerte campaña de fiscalización del comercio ilegal realizada por el Municipio de Santiago. Se observó una rápida desaparición de los vendedores ambulantes y una consolidación de la ocupación legal por parte de los migrantes en su mayoría peruanos.

“...el 90\% de ellos se ha logrado formalizar (...). Todos han realizado su iniciación de actividades, extienden sus boletas, tienen sus contratos de arriendo, pagan sus impuestos y otorgan un mejor servicio a sus clientes, ya no en la calle, sino que ahora en sus locales" (Diario Contigo Perú, diciembre de 2007).

El sueño expresado por los entrevistados peruanos del área es transformar esta galería en un mall, con patio de comidas peruanas, de manera de construir un espacio abierto a las distintas expresiones de la peruanidad. Dado el vigor que muestra el proceso de cambio, no parece extraño que ese sueño pueda ser alcanzado.

Esta "extensión" de la capital peruana en tierras chilenas está empezando a propagarse por otros sectores cercanos al centro de Santiago, y es especialmente notable en la Vega Central y en ciertos sectores de la comuna de Independencia. En la Vega Central, alrededor del año 2000, se empiezan a instalar algunos 
comerciantes peruanos que ofrecen productos que se importan desde el Perú, multiplicándose a tal nivel que en el año 2010 se reconoce en la Vega que lo que antes se llamaba "el callejón de las ánimas" - por su abandono- ahora es conocido como "el pasillo de los peruanos". La gran demanda por productos peruanos no sólo proviene de los miles de peruanos residentes en las cercanías de la Vega (comunas de Recoleta e Independencia) y en el centro, sino también de muchos chilenos que han incorporados estos productos a su vida cotidiana. Julio Jibala, comerciante peruano, cuenta que se están organizando para formar una Asociación de Comerciantes Peruanos de la Vega, “...de tal manera que el gobierno peruano nos conozca y nos apoye", iniciativa alentada por la visita a la Vega Central de la ministra de Comercio Exterior y Turismo de Perú, quien les ofreció exportación de productos peruanos a menor valor.

FIGURA 6 | Uso comercial Galería Bandera Centro (Catedral/Bandera)

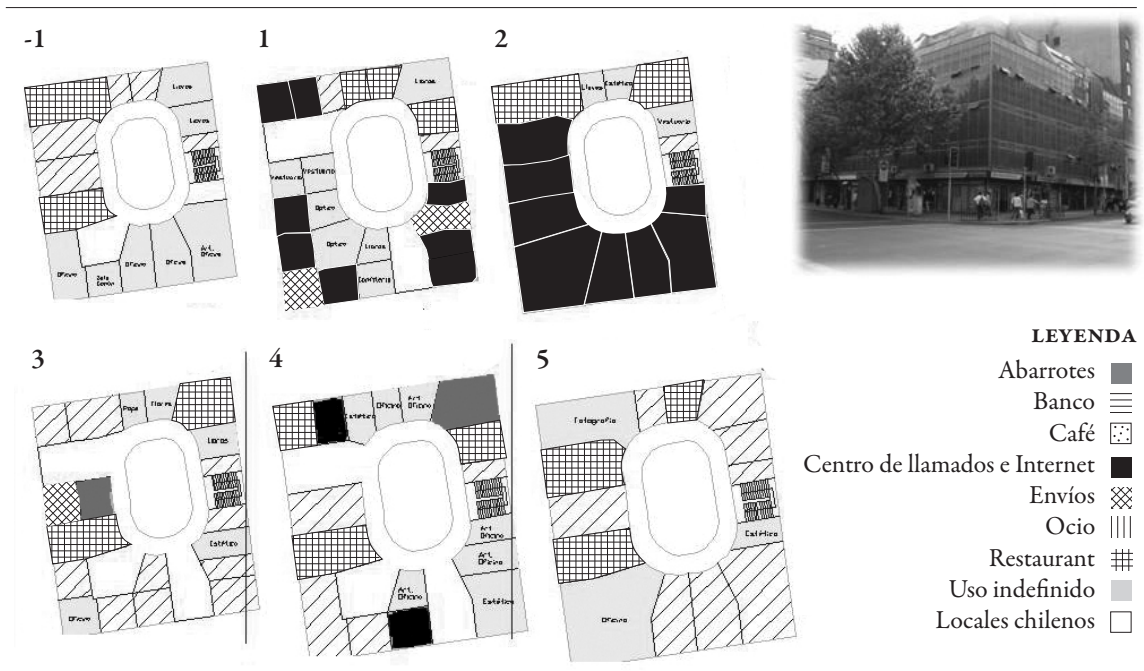

FUENTE ELABORACIÓN PROPIA.

Por otra parte, también ya se visualiza un nuevo "barrio peruano" en la comuna de Independencia, donde, desde principios de la década de 2000, han estado llegando cientos (¿miles?) de migrantes peruanos que arriendan casas y piezas. La proximidad con el centro, los comercios y el mercado de la Vega actúan como foco de atracción para una comunidad que valora la cercanía y busca evitar el tiempo y costos que involucra el transporte. Esto ha dado nacimiento a un nuevo "barrio peruano", en torno a la calle Rivera (colindante con Maruri, Independencia y Picarte), donde se pueden encontrar puestos de venta ambulante de salchipollos, salchipapas y anticuchos de corazón, además de media docena de centros de llamados, peluquerías y alguna tienda de productos peruanos. 
FIGURA 7 | Almacenes calle Rivera, Independencia

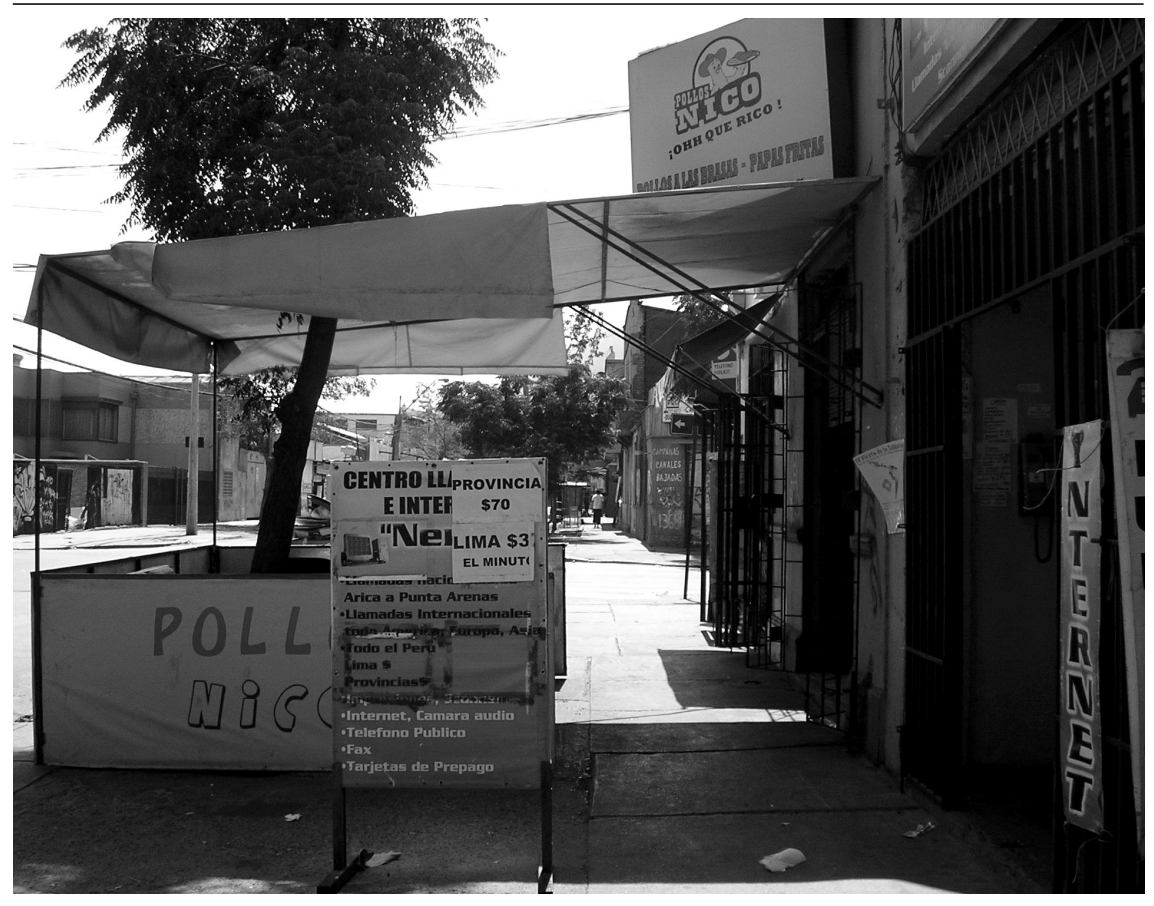

FUENTE AUTORAS.

Estos nuevos comercios y la creciente presencia de peruanos han producido un cambio de paisaje en el barrio, el cual es recordado como un lugar sin vida y peligroso.

"Cuando yo vivía allí no había nadie. Nada que ver con ese ambiente que hay ahora, que parece Perú (...). Hoy ya no hay delincuencia (...) y los negocios han prosperado mucho por la presencia de los compatriotas" (Líder Núñez, peruano dueño de un restaurante del centro de Santiago, quien hace cuatro años vivió en calle Rivera).

En estos lugares, la presencia de los nuevos inmigrantes está sirviendo también como motor de cambio y desarrollo para ciertas áreas centrales de la ciudad, las que por su propia decadencia anterior han permitido esta invasión gradual de nuevas actividades y habitantes.

\section{Discusión final: Santiago, ¿̨una ciudad cosmopolita?}

El fenómeno de las intensas corrientes migratorias que están llegando a Chile en los últimos años es, en nuestra opinión, uno de los hechos sociológicos en desarrollo más interesantes en el país y, de continuar las actuales tendencias, pasará a ser un tema central de la agenda política del país en pocos años. 
Esta situación tiene algunas similitudes con la experimentada en las primeras décadas del siglo XX, cuando Estados Unidos recibía migrantes pobres de Europa. Estos también se tomaron zonas centrales abandonadas de la ciudad, y generaron lo que los ecólogos de Chicago llamaron "ghettos", algunos de los cuales dieron origen al China Town de San Francisco o a la Pequeña Italia de Nueva York (Park, 1925, 1928).

Por otra parte, la fuerza de cambio y de desarrollo económico que están generando los migrantes en las áreas que ocupan, aparece en algo que planteaba Castells en 1983 sobre la acción de los grupos gay en San Francisco, California:

...una proporción muy significativa de la renovación de las viviendas y del mejoramiento de los barrios parece haber sido resultado de los grandes esfuerzos realizados por gays de rentas moderadas que hicieron especiales esfuerzos invirtiendo su tiempo y trabajo para compartir un pequeño espacio de vivienda a cambio de la sensación de libertad, protección y autoexpresión que les permitía ese territorio (Castells, 1983, p. 166).

También el economista Richard Florida en sus libros sobre lo que llama la "clase creativa”, observó que algunos grupos sirven como fuerza innovadora y recuperan sectores de ciudades de Estados Unidos. Al igual que los gays que estudia Castells, o los jóvenes bohemios que observa Florida, los inmigrantes están transformando ciertas zonas decadentes de la ciudad de Santiago y abriendo nuevas vetas económicas en ellas. Aunque estos inmigrantes provienen de sectores sociales de recursos medio-bajos o bajos, al igual que los anteriores, están desarrollando la creatividad, la tolerancia y generando lugares de recreación (amenities), elementos fundamentales, según Florida, para producir prosperidad económica en un lugar (2002).

Sin embargo, aunque esta capacidad que tiene la instalación de los nuevos migrantes para producir cambios en zonas abandonadas de la ciudad es innegable, también debe reconocerse que no todos los resultados son positivos. Si bien hay beneficios visibles en la Pequeña Lima, zona a la que han aportado nueva vitalidad, aumentando el valor de sus arriendos y el flujo de personas hacia el centro de Santiago, la ocupación de antiguas casonas que se arriendan por piezas a los recién llegados en las zonas cercanas está generando una situación explosiva que puede traer consecuencias muy negativas en el mediano plazo. De hecho, resulta cada vez más frecuente en las noticias ver viviendas de renta en la zona central incendiadas por el exceso de instalaciones eléctricas informales, común en las casonas que se arriendan por piezas. Ahí asoma el nivel de precariedad y hacinamiento que están enfrentando los recién llegados de menores recursos.

Desde otro ángulo, siguiendo a Mazurek, la pequeña Lima representa claramente la conformación de una "nueva territorialidad" o la apropiación de un nuevo espacio que tiene fuertes referencias con el espacio de origen: “...podríamos hablar de una "transterritorialidad" donde el espacio ya no es totalmente físico ni el proceso de apropiación totalmente cultural". Se ha transformado en un "barrio étnico" que, como "espacio identitario", permite a los migrantes recuperar su identidad y visualizar la migración, no sólo como un viaje "doloroso", “...sino como la posible construcción de nuevos espacios de construcción identitaria” (2009, pp. 18, 21). 
La importancia que está adquiriendo la celebración de las fiestas peruanas en el paisaje urbano de Santiago, queda evidenciada a través de las reacciones de la prensa nacional que, año a año, hacen más visibles estas actividades para el público chileno. Estas celebraciones son símbolos de pertenencia y son elementos clave para mantener el arraigo al origen, "...son los elementos de conformación de una identidad multipolar que se inscribe en esta nueva territorialidad” (Mazurek, 2009, p. 19).

La potencia de la "peruanidad" que traen los migrantes consigo está produciendo impactos culturales notorios en Chile, y esto tiene relación con lo que Altamirano destaca: "Los valores culturales como son la lengua, la comida, la música, el arte, el baile, etcétera, han sido transportados por los peruanos a todos los confines de la tierra, es decir, la cultura peruana está en proceso de globalización. El migrante peruano se ha convertido en el promotor más activo de nuestra cultura en el exterior" (Altamirano, 1999a, p. 11).

Con relación al tema de la discriminación que perciben los peruanos, la "teoría de la amenaza grupal" plantea que la hostilidad y los prejuicios que se desarrollan entre distintos grupos tiene que ver con la amenaza que un grupo mayoritario siente cuando aparece un grupo menor que puede ser considerado inferior y/o muy distinto por el grupo dominante, el cual viene a apropiarse de algunos beneficios que el grupo dominante considera propios (Blumer, 1958, citado por Rink et al., 2009). El prejuicio es, ante todo, una respuesta a una amenaza colectiva real, más que sólo a una amenaza percibida, cuando un grupo externo desafía los intereses de un grupo dominante. Típicamente, el conflicto grupal se caracteriza por una creencia de suma cero: la ganancia de un grupo es pérdida para el otro (Bobo, 1996). Estos miedos pueden parecer irracionales, pero la migración internacional genera conflictos de interés genuinos, así como choques entre derechos humanos y de libertad incompatibles. Los residentes originales quieren proteger lo que es suyo de los forasteros, mientras que los migrantes quieren viajar libremente y ganar lo mejor posible. Estas disputas no son siempre insolubles o permanentes: han sido enfrentadas en el pasado y, si bien no completamente resueltas, al menos han sido acomodadas. Las mezclas de raza, cultura y estilo de vida se han asentado en coexistencia pacífica y dado origen a nuevas sociedades vigorosas e innovadoras (Stalker, 1994, pp. 4-5).

Las migraciones masivas conllevan necesariamente procesos de "aculturación", cuando grupos de personas y sus miembros se involucran en contactos interculturales. Ambos grupos desarrollan estrategias de aculturación, se producen cambios de comportamiento y surgen situaciones de stress, todo lo cual produce un potencial de conflicto que requiere desarrollar procesos de negociación que permitan la adaptación de ambas partes. Frente a esta situación, surgen distintas posibilidades de reacción: una es aceptar el pluralismo cultural, tomando medidas para apoyar la continuación de la diversidad cultural (ideología multicultural positiva), y supone una estrategia de integración que involucra compromisos por ambas partes. La otra, es el intento de eliminar la diversidad por medio de políticas y programas de asimilación y, por último, está el intento por segregar y marginalizar las poblaciones "diversas" (Berry, 2005). 
Lo anterior muestra la importancia que tiene el que el país desarrolle una postura frente al fenómeno, ya que las políticas públicas orientadas a las nuevas migraciones son indispensables para, además de prevenir la generación de conflictos, facilitar una adecuada integración de los inmigrantes al país. La falta de previsión de las necesidades de los recién llegados está incubando un problema potencialmente explosivo, al no existir sistemas (públicos o privados) para responder adecuadamente a ellas, sean de vivienda, salud y/o educación. Resulta urgente contar con herramientas y conocimiento suficiente para afrontar este nuevo escenario, el que, tratado en forma apropiada, puede ser fuente de desarrollo y prosperidad para el país.

Finalmente, es fundamental cambiar la perspectiva de "problema" con que se enfrentan las migraciones, descubriendo sus aspectos positivos y aprovechando su potencial. Así, además de entender y prever los problemas que se pueden generar, podemos estar preparados -como sociedad y como país- para enfrentar un fenómeno social que, según todos los indicios, seguirá creciendo y generando nuevos espacios identitarios que enriquecen, no sólo a los que llegan, sino al país que los acoge. IEURE

\section{Referencias bibliográficas}

Altamirano, T. (2004). Transnacionalismo, remesas y economía doméstica. Cuadernos Electrónicos de Filosofía del Derecho, no 10/2004, http://www.uv.es/

Altamirano, T. (1999a). Los peruanos en el exterior y su revinculación con el Perú. En Academia Diplomática del Perú, Comunidades Peruanas en el Exterior: Situación y Perspectivas, pp. 26-45.

Altamirano, T. (1999b). Patrimonio y procesos culturales en Centros Históricos. Ponencia presentada al Seminario Taller FLACSO, Quito, septiembre. http://www.flacso.org.ec/docs/sfdesculaltamirano.pdf

Berry, J. W. (2005). Acculturation: Living successfully in two cultures. International Journal of Intercultural Relations, Volume 29, Issue 6, Nov., Pages 697-712.

BID (2004). Remesas hacia América Latina y El Caribe. Metas y recomendaciones. Lima, Perú, marzo 27.

Bobo, L. \& Hutchings, V. L. (1996). Perceptions of Racial Group Competition: Extending Blumer's Theory of Group Position to a Multiracial Social Context. American Sociological Review, Vol. 61, No. 6 (Dec., 1996), pp. 951-972.

CEPAL (Comisión Económica para América Latina y El Caribe) (2002): Panorama social de América Latina. Santiago.

Cultura en movimiento (2007). http://www.culturaenmovimiento.cl

De los Ríos, J. \& Rueda, C. (2005). ¿Por qué migran los peruanos al exterior? Economía y Sociedad, 58, CIES, diciembre.

Diario Contigo Perú: diferentes fechas.

Diario Latin America (agosto 2002). Peruanos de la Pequeña Lima. ¿Quiénes son? ¿De qué los acusan?

Escrivá, Á. (2002). ¿Empleadas de por vida? Peruanas en el servicio doméstico de Barcelona. Revista Papers, $\mathrm{N}^{\circ} 60$.

Feldman, D. (2007). Global Movements, Internal Migration, and the Importance of Institutions. International Review of Social History, vol. 52.

Florida, R. (2002). The Rise of the Creative Class: And How It's Transforming Work, Leisure, Community and Everyday Life. New York: Basic Books.

Gregorio Gil, C. (1998). Migración femenina. Su impacto en las relaciones de género. Madrid: Narcea.

Hall. P. (2000). La Redefinición de las Ciudades Europeas. En: C. Bellet, C. Llop (Eds.). Ciudades intermedias, urbanización y sostenibilidad. Lleida: Pagès editors. 
Instituto Nacional de Estadísticas. INE. (2007). CENSO Población y Vivienda 2002. Santiago, Chile. Jiménez, C. (2003). Qué es la inmigración. Madrid: Integral.

Marmora, L. (2002). Las Políticas de Migraciones Internacionales. Buenos Aires: Paidós.

Martínez, J. (2002). Exigencias y posibilidades para políticas de población y migración internacional. El contexto latinoamericano y el caso de Chile. Serie Población y Desarrollo, $\mathrm{n}^{\circ} 24$. CELADE. Santiago de Chile.

Martínez, J. (2003). El encanto de los datos. Sociodemografía de la inmigración en Chile según el censo de 2002. Santiago de Chile: CEPAL.

Mazurek, H. (2009). Migraciones y dinámicas territoriales. En C. Salazar, CAF-CIDES-UMSA (Eds.). Migraciones contemporáneas. Contribución al debate. La Paz: Plural editores.

Mujica, J. (2004). El desafío de la solidaridad: condiciones de vida y de trabajo de los migrantes peruanos en Chile. Serie Documentos de trabajo N 178. Lima, OIT.

Naciones Unidas. (2005) Trends in Total Migrant Stock: the 2003 Revisión. En OIM International Organization for Migration. World Migration Report 2005. Base de datos mantenida por la División de Población del Departamento de Asuntos Económicos y Sociales.

Norambuena, C. (2004). Chile y sus Nuevos Inmigrantes. Ni acogidos ni rechazados. Revista Universitaria No 85. Instituto de Estudios Avanzados de la Universidad de Santiago de Chile.

OIM. International Organization for Migration (2002). Hechos y cifras sobre la migración Internacional. International Migration Report. Serie cuestiones políticas e investigación sobre migraciones $\mathrm{N}^{\circ} 2$.

OIM. International Organization for Migration (2003). Hechos y cifras sobre la migración Internacional. International Migration Report. Serie cuestiones políticas e investigación sobre migraciones $\mathrm{N}^{\circ} 2$.

OIM -Chile (2002). Informe Síntesis. Estudio exploratorio diagnóstico y percepción sobre migración limitrofelfronteriza en Chile. Santiago: OIM.

Park, R. E.; McKenzie, R. D. \& Burgess, E. (1925). The City: Suggestions for the Study of Human Nature in the Urban Environment. Chicago: University of Chicago Press.

Park, R. E.; McKenzie, R. D. \& Burgess, E. (1928). Human Migration and the Marginal Man. American Journal of Sociology, 33.

Portes, A. (2009). Migración y desarrollo: una revisión conceptual de la evidencia. En C. Salazar, CAFCIDES-UMSA (Eds.). Migraciones contemporáneas. Contribución al debate. La Paz: Plural editores.

Reyes, N. (2007). Inmigrantes peruanas en Santiago. El desafio de la inserción laboral. Memoria, International Master of Advanced Studies en Estudios de Desarrollo - IMAS.

Rink, N.; Phalet, K. \& Swyngedouw M. (2009). The Effects of Immigrant Population Size, Unemployment, and Individual Characteristics on Voting for the Vlaams Blok in Flanders 1991-1999. European Sociological Review, Vol. 25 n. $42009411-424$.

Robert, E. (2009. Mujeres, migración, remesas y relaciones de género. Evidencias a partir de tres casos: Colombia, República Dominicana y Guatemala. En C. Salazar, CAF-CIDES-UMSA (Eds.). Migraciones contemporáneas. Contribución al debate. La Paz: Plural editores.

Sassen, S. (2003). Los espectros de la globalización. México: Fondo de Cultura Económica.

Solé, C. (2000). El Impacto de la Inmigración en la sociedad receptora. REIS, Revista Española de Investigación Sociológica. No 90.Cis, pp. 131-157.

Solimano, A. \& Tokman, V. (2006). Migraciones internacionales en un contexto de crecimiento económico. El caso de Chile. Serie macroeconomía del desarrollo n 54. CEPAL.

Stalker, P. (1994). The work of strangers: A survey on international migration. Geneva: International Labour Office.

Stefoni, C. (2002). Mujeres inmigrantes peruanas en Chile. Papeles de Población No 33. FLACSO.

Stefoni, C. (2004). Inmigración y Ciudadanía: la formación de comunidades peruanas en Santiago y la emergencia de nuevos ciudadanos. Papeles de Población No 43. FLACSO.

Stefoni, C. (2005). Migración en Chile. Colección ideas. Año 6, n. 59. Santiago de Chile. 


\section{Anexo: nota metodológica}

Este trabajo se basa en una investigación con un énfasis cualitativo que incluyó, además de un levantamiento de la ocupación del espacio en la zona conocida como la "Nueva Lima", la realización de entrevistas con informantes clave y de historias de vida de siete inmigrantes peruanos, además de acompañar sus trayectorias por la ciudad y compartir con ellos algunas actividades. Los eventos colectivos donde se realizó observación etnográfica fueron: el Partido Chile-Perú por las eliminatorias para el mundial de Sudáfrica 2010 en el Bar Conga Latina (17 octubre 2007), la Procesión del Señor de los Milagros (27 de octubre 2007), el Primer Concurso Nacional de Marinera (11 de noviembre 2007) y análisis en terreno del comercio y las iteracciones en la calle Catedral (noviembre 2007). 